\title{
Penguatan Personal Branding Siswa Melalui Pendidikan Kecakapan Hidup (Life Skills Education) Di SD Islam Terpadu Logaritma Karanganyar Kebumen
}

\author{
Titi Maemunah \\ Institut Agama Islam Nahdlatul Ulama Kebumen \\ dstitm.020171@umnu.ac.id
}

\begin{abstract}
Abstrak
Dalam rangka memberdayakan generasi muda bangsa, pendidikan harus dikembangkan secara dinamis dengan selalu mengikuti berbagai perkembangan yang terjadi dalam masyarakat. Dengan demikian, lembaga pendidikan harus dapat digunakan sebagai pusat pengembangan intelegensi dan kepribadian yang mampu memberikan warna dan karakter generasi yang kuat. Pengembangan sistim pendidikan yang kontekstual dan inovatif menjadi upaya positif bagi lembagalembaga penyelenggara pendidikan dalam menyiapkan generasi bangsa yang benar-benar berkualitas, mandiri dan dapat diandalkan. Oleh karena itu SD IT Logaritma selain memberikan bekal ilmu umum dan agama juga melakukan upaya penguatan personal branding melalui pendidikan life skill untuk siswa agar bisa survive the life. Penelitian ini menggunakan pendekatan kualitatif dengan jenis penelitian studi kasus. Teknik pengumpulan data dengan observasi, wawancara dan dokumentasi. Teknik analisis data menggunakan metode induktif, deduktif intepretasi data dan metode komparatif. Hasil penelitian menunjukan bahwa upaya Penguatan Personal Branding Siswa Melalui Pendidikan Kecakapan Hidup (Life Skills Education) di SD IT Logaritma Karanganyar Kebumen, sudah cukup baik. Life skill yang dikembangkan di SD IT Logaritma Karanganyar Kebumen, meliputi personal skill, thingking skill, sosial skill, academic skill dan vocasional skill. Kondisi ini didukung oleh keterampilan yang diberikan diminati oleh siswa, terlihat dari keaktifan siswa selama kegiatan berlangsung. Komposisi materi lebih banyak praktek daripada teori yang diberikan kepada siswa. Penggunaan metode dan pendekatan sudah tepat sesuai materi pembelajaran dan kondisi siswa. Selain itu upaya pengembangan life skill dilakukan dengan tiga tahap yaitu tahap pengajaran, pembiasaan dan penugasan, tiga proses perencanaan, pelaksanaan dan evaluasi.
\end{abstract}

Kata Kunci: Penguatan Diri, Pendidikan, Keahlian, Kecakapan Hidup

\begin{abstract}
In order to empower the nation's young generation, education must be developed dynamically by following various progress that occurs in society. Thus, educational institutions must be functioned as the center for the development of intelligence and personality that are able to provide a strong generation and character. The development of a contextual and innovative education system becomes a positive effort for education institutions in preparing a truly qualified, independent and reliable generation of the nation. Therefore, SD IT Logaritma,
\end{abstract}


apart from providing general knowledge and religion, also conducts personal branding through life skills education for students to survive the life. This research uses a qualitative approach with the type of case study research. Data collection techniques used are observation, interviews and documentation. While the data analysis technique used are inductive methods, deductive data interpretation and comparative methods. The result showed that the efforts to strengthen Student Personal Branding through Life Skills Education at SD IT Logaritma Karanganyar, Kebumen, were good enough. Life skills developed at SD IT Logaritma Karanganyar, Kebumen, included personal skills, thinking skills, social skills, academic skills and vocational skills. This condition was supported by the skills that students were interested to, it was shown from the activeness of students during the activity. The composition of the material was more practical than theoretical. The use of methods and approaches was appropriate according to the learning material and student conditions. In addition, the efforts to develop life skills were carried out in three stages, teaching; habituation and assignment stages; three processes of planning; implementation; and evaluation.

Keywords: Personal Branding, Education, Life Skills, Life Skill Education

\section{Pendahuluan}

Modernisasi kehidupan yang menyentuh semua aspek kehidupan akibat revolusi ilmu pengetahuan dan teknologi meniscayakan semua pihak untuk meresponnya secara aktif dan kontekstual. Masalah-masalah kontemporer yang datang silih beganti menuntut partisipasi aktif pesantren/dunia pendidikan Islam untuk ikut memberikan kontribusi maksimal agar mampu memandu gerak dinamika sejarah dengan nilai-nilai sucinya (Asmani, 2011).

Dalam rangka memberdayakan generasi muda bangsa, pendidikan harus dikembangkan secara dinamis dengan selalu mengikuti berbagai perkembangan yang terjadi dalam masyarakat. Pengembangan sistim pendidikan yang kontekstual dan inovatif pada dasarnya dapat menjadi upaya positif bagi lembaga-lembaga penyelenggara pendidikan dalam menyiapkan generasi bangsa yang benar-benar berkualitas, mandiri dan dapat diandalkan. Untuk itu, dalam konteks yang lebih spesifik penyelenggara pelayanan pendidikan harus mampu menggabungkan antara teori dan praktik secara seimbang (FIP-UPI, 2007).

Pembentukan karakter merupakan salah satu tujuan pendidikan nasional. Pasal I UU Sisdiknas No. 20 tahun 2003 menyatakan bahwa di antara tujuan pendidikan nasional adalah mengembangkan potensi peserta didik untuk memiliki kecerdasan, kepribadian dan akhlak mulia. Amanah UU Sisdiknas tahun 2003 itu bermaksud agar pendidikan tidak hanya membentuk insan Indonesia yang cerdas, namun jugaberkepribadian atau berkarakter, sehingga nantinya akan lahir generasi bangsa yang tumbuh berkembang dengan karakter yang yang bernafas nilai-nilai luhur bangsa serta agama (Alfiah, 2020)

Kegiatan Pendidikan berintikan interaksi antara peserta didik dan sumber-sumber pendidikan lain, dan berlangsung dalam suatu lingkungan pendidikan. Kegiatan pendidikan berfungsi membantu mengembangkan potensi, kecakapan dan karakteristik peserta didik agar berkembang sesuai dengan harapan masyarakat.Tujuan pendidikan merupakan sasaran-sasaran 
Universitas Ma'arif Nahdlatul Ulama Kebumen yang harus dicapai atau dikuasai oleh peserta didik untuk kehidupannya sebagai pribadi, warga masyarakat, belajar lebih lanjut dan melaksanakan tugas-tugas pekerjaan.

Perbedaan pendidikan dengan pengajaran terletak pada penekanan pendidikan terhadap pembentukan kesadaran dan kepribadian anak didik disamping transfer ilmu dan keahlian. Dengan proses semacam ini suatu bangsa atau negara dapat mewariskan nilai-nilai keagamaan, kebudayaan, pemikiran dan keahlian kepada generasi mudanya, sehingga mereka betul-betul siap menyongsong kehidupan (Azra, 2000).

Pengertian pendidikan secara umum, yang kemudian dihubungkan dengan Islam sebagai suatu sistem keagamaan yang menimbulkan pengertian-pengertian baru, dimana secara implisit menjelaskan karakteristik-karakteristik yang dimilikinya. Dalam rangka yang lebih rinci, Qardhawi tahun 1980 memberikan pengertian, bahwa; "pendidikan Islam adalah pendidikan manusi seutuhnya; akal dan hatinya; rohani dan jasmaninya; akhlak dan ketrampilannya. Karena itu,pendidikan Islam menyiapkan manusia untuk hidup baik dalam keadaan damai maupun perang, dan menyiapkannya untuk menghadapi masyarakat dengan segala kebaikan dan kejahatannya, manis dan pahitnya (Qardhawi, 1980).

Dari pengertian di atas terlihat penekanan pendidikan Islam pada "bimbingan". Bukan "pengajaran" yang mengandung konotasi otoritatif pihak pelaksana pendidikan, katakanlah guru. Dengan bimbingan sesuai dengan ajaran-ajaran Islam, maka anak didik mempunyai ruang gerak yang cukup luas untuk mengaktualisasikan segala potensi yang dimilikinya. Disini sang guru, lebih berfungsi sebagai "fasilitator" atau penunjuk jalan ke arah penggalian potensi anak didik. Dengan demikian, guru bukanlah segala-galanya, sehingga cenderung menganggap anak didik bukan apa-apa, selain manusia yang masih kosong yang perlu diisi. Dengan kerangka dasar pengertian ini, maka guru menghormati anak didik sebagai individu yang memiliki berbagai potensi (Azra, 2000).

Untuk menjadi pribadi yang siap bergulat, bersaing dan berkompetisi serta bermanfaat untuk diri, keluarga dan masyarakat di era globalisasi ini, maka manusia, individu, siswa, anak didik harus punya keahlian/identitas/merk/personal branding yang kuat. Dalam hal ini kegiatan pendidikan berfungsi membantu mengembangkan potensi, kecakapan dan karakteristik peserta didik agar berkembang sesuai dengan harapan masyarakat. Untuk membangun personal branding, dapat melalui pengembangan potensi, kecakapan dan karakteristik peserta didik agar berkembang sesuai dengan kebutuhan dan harapan masyarakat, sesuai dengan fungsi pendidikan itu sendiri.

Menurut Ghodeswar, branding berarti membedakan nama dan atau simbol, seperti logo, merek dagang, atau desain dengan maksud mengidentifikasi dan membedakan produk. Branding juga dapat diartikan sebagai usaha untuk membedakan produk kita dengan produk pesaing kita sehingga akan memberikan keuntungan kompetitif di pasaran (Sutrisna, 2010).

Pada perkembangannya, istilah brand tidak hanya dipakai untuk menandai suatu hasil produksi maupun jasa saja. Individu dan organisasi juga dapat dilihat sebagai brand. Individu dan organisasi juga dapat digambarkan oleh orang lain sebagai brand yang dimengertidan disukai atau tidak disukai oleh orang lain. Misalnya saja politisi, atlet profesional, atau selebritis dan publik figur lain, mereka seakan berlomba-lomba untuk mendapatkan persetujuan dan 
penerimaan dari publik dengan menyampaikan gambaran yang kuat dan diinginkan publik, Brand yang dimiliki individu ini disebut sebagai "Personal Brand".

Personal brand tidak hanya dimiliki oleh publik figur atau orang terkenal. Siapapun yang sedang membangun karir maka mereka dapat membangun personal brand mereka sendiri sesuai dengan objektif masing-masing. Dengan membangun nama dan reputasi yang bagus, individu pada dasarnya telah menciptakan personal brand mereka sendiri. Dengan personal brand yang baik, maka bisa diibaratkan bahwa produk yang di jual akan lebih menarik bagi individu lain untuk membelinya. Maka sangat perlu bagi seorang individu untuk mempersiapkan diri untuk memiliki personal brand yang positif.

Sebuah brand yang melekat pada individu tidak serta merta dapat dibangun dengan mudah begitu saja. Dalam personal brand terdapat tiga elemen pembentuk yaitu penampilan, kepribadian dan karakter. Sejatinya brand yang ada dalam tiap individu tumbuh dan berkembang dari kegiatan-kegiatan yang dilakukan. Melalui kecakapan hidup, seorang harus mampu melakukan eksplorasi berbagai alternatif, menimbang baik yang menguntungkan maupun yang merugikan dan membuat keputusan yang rasional dalam mememcahkan masalah dan isu yang ada. Pada esensinya kecakapan hidup adalah keterampilan siswa untuk memahami dirinya dan potensinya dalam kehidupannya, antara lain mencakup penentuan tujuan, memecahkan masalah dan hidup bersama orang lain. Keterampilan-ketermpilan tersebut akan membantunya untuk kehidupan dalam lingkungannya dan mencapai kesehatan serta memiliki perilaku yang produktif. Penelitian ilmiah menunjukan bahwa life skills education membantu siswa untuk melindungi dirinya dari berbagai bahaya, bukan hanya obat terlarang tetapi lebih dari itu untuk megajarkan basic life skils kepada anak remaja untuk memasuki kehidupan sebagai orang dewasa yang berhasil.

Harapannya dengan bekal personal brand dan ilmu kecakapan hidup (life skill) yang kuat dan baik, seseorang, individu, siswa atau santri akan bisa menghadapi pergulatan dan persaingan hidup di era globalisasi ini. Dimana yang mempunyai personal brand/skill yang kuat yang bisa bersaing dan bertahan. Dalam hal seperti ini, kebijakan pendidikan dalam pembangunan Sumber Daya Manusia (SDM) di Indonesia bukan hanya tanggungjawab lembaga pendidikan formal atau umum, akan tetapi lembaga pendidikan non formalpun punya tanggungjawab yang sama, pesantren/lembaga pendidikan (Anwar M. A., 2017).

Dengan segala kondisi dan permasalahan yang ada, maka tugas dari lembaga pendidikan baik formal maupun non formal, harus berusaha dengan keras mengejar ketertinggalannya dengan mencurahkan segala kemampuan untuk menguasai ilmu pengetahuan dan teknologi secara dinamis dan progresif agar bisa survive dan dapat memenuhi tuntutan masyarakat dengan melalui pendidikan yang berorientasi pada pembangunan personal branding dengan melalui pengembangan life skill. (Hasanah, 2019)

Dalam upaya menyiapkan SDM berkualitas, maka setiap daerah, setiap perguruan tinggi dan setiap sekolah boleh melebihi standar yang dipersyaratkan sesuai kemampuan dan kreatifitas masing-masing. Kemampuan melampaui standar inilah yang memberi ruang kepada setiap daerah dan lembaga pendidikan untuk memperkuat human capital dalam menentukan kebijakan meningkatkan kualitas SDM yang memiliki daya saing dalam hal skill, kompetensi, pengetahuan, dan kapabilitas. (Sagala, 2017) 
Universitas Ma'arif Nahdlatul Ulama Kebumen

Menyadari pentingnya proses peningkatan kualitas sumber daya manusia, maka pemerintah bersama kalangan swasta sama-sama telah dan terus berupaya mewujudkan amanat tersebut melalui berbagai usaha pembangunan pendidikan yang lebih berkualitas atau bermutu. Problematika yang dihadapi lembaga pendidikan Islam begitu beragam. Mulai dari problem manajemen, problem kepemimpinan, sumber daya manusia, finansial, dan problem kelembagaan. Peningkatan mutu lembaga pendidikan Islam perlu terus diupayakan dengan mengedepankan teori-teori analisis mutu dan penerapannya.

SD Islam Terpadu Logaritma Karanganyar merupakan salah satu sekolah favorit dan dipercaya oleh masyarakat, dibandingkan sekolah yang sejenis yang ada di Sub Rayon Karanganyar. Indikasi keberhasilan SD ini dapat dilihat dari beberapa faktor diantaranya walaupun bangunan sekolah tidak begitu mewah akan tetapi cukup nyaman untuk belajar, terletak di pusat kota Karanganyar. Selain itu, faktor kepemimpinan kepala sekolah dan juga profesionalisme para ustadz dan ustadzahnya dalam mendampingi peserta didik dalam proses belajar mengajar sehingga mampu menciptakan prestasi akademik yang di raih oleh SD Islam Terpadu Logaritma Karanganyar Kebumen selama ini. Hal tersebut yang membuat minat peserta didik dan orang tua siswa yang tinggi untuk bersekolah dan menyekolahkan anaknya di SD Islam Terpadu Logaritma Karanganyar Kebumen ini.

Berdasarkan latar belakang yang telah dipaparkan disertai keinginan yang lebih mendalam mengenahi upaya penguatan personal branding siswa melalui pendidikan kecakapan hidup (life skills education), maka peneliti akan mengadakan penelitian dengan judul "Penguatan Personal Branding Siswa melalui Pendidikan Kecakapan Hidup (Life Skills Education) di SD Islam Terpadu Logaritma Karanganyar Kebumen".

\section{Metodologi Penelitian}

Jenis Penelitian yang penulis gunakan dalam penelitian ini yaitu penelitian kualitatif, dimana penelitian kualitatif adalah penelitian yang digunakan untuk meneliti pada kondisi obyek yang alamiah, dimana peneliti sebagai instrumen kunci. Penulis menggunakan metode kualitatif karena ada beberapa pertimbangan antara lain, menjelaskan menyesuaikan metode kualitatif lebih mudah apabila berhadapan dengan kenyataan-kenyataan ganda, metode ini menyajikan secara langsung hakikat hubungan antara peneliti dan responden, metode ini lebih peka dan lebih dapat menyesuaikan diri dengan banyak penajaman pengaruh bersama dan terhadap pola-pola nilai yang dihadapi. Penelitian dilakukan di SD Islam Terpadu Logaritma Karanganyar Kebumen. Metode penelitian menggunakan metode deskriptif.

Teknik pengumpulan data dilakukan dengan teknik observasi, wawancara, studi dokumentasi dan triangulasi/gabungan. Peneliti melakukan observasi melalui pengamatan baik secara langsung maupun tidak langsung dengan menggunakan seluruh pancaindra. Wawancara dengan percakapan dan tanya jawab untuk mendapatkan informasi dari narasumber. Studi dokumentasi dilakukan untuk mengumpulkan dokumen dan data-data pendukung terkait dengan penelitian. Triangulasi yaitu dengan cara mengumpulkan data dari berbagai sumber yang sekaligus menguji kredibilitas data (Sugiyono, 2014). Proses analisa data kuantitatif dilakukan melalui tiga alur kegiatan yang terjadi bersamaan, yakni reduksi data, penyajian data, dan penarikan kesimpulan. 


\section{Hasil dan Pembahasan}

SD IT Logaritma Karanganyar terletak di wilayah kecamatan Karanganyar, Kabupaten Kebumen. Karanganyar sendiri merupakan salah satu wilayah di Kabupaten Kebumen. SDIT berdiri di bawah naungan Yayasan Bina Insan Kebumen yang kantor pusatnya terletak di Jalan Raya Sokka, Widara Payung, Kedawung, Pejagoan, Kebumen. Seluruh pihak yang ada di SD IT Logaritma Karanganyar mayoritas bahkan seluruhnya beragama Islam. Yayasan Bina Insani Kebumen memiliki tujuan untuk membentuk masyarakat islami yang menerapkan syariat Islam dalam kehidupan sehari-hari agar selamat baik di dunia maupun di akhirat. Adapun salah satu usaha dalam memenuhi harapan masyarakat akan pendidikan dasar dan keagamanan bagi anakanak, Yayasan Bina Insani Kebumen mendirikan Sekolah Dasar Islam Terpadu (SDIT) Logaritma. SDIT ini berdiri secara resmi pada tanggal 04 Februari 2006, berdasarkan Surat Keterangan Pendirian Sekolah dan izin Operasional Nomor 421/261 tanggal 04 Februari 2006.

Sederet prestasi yang berhasil diraih oleh SD IT Logaritma sudah membuktikan bahwa sekolah tersebut senantiasa berusaha untuk memberikan yang terbaik bagi siswa-siswinya, baik dalam bidang akademik maupun fasilitasi bakat dan minat yang diwadahi dalam kegiatan ektrakulikuler serta bina prestasi. Tujuannya adalah untuk membentuk karakter peserta didik sesuai dengan ketertarikan serta bakat minat anak itu sendiri, menyalurkan potensi anak didik agar mencapai taraf maksimum serta memperluas pengalaman sosial dalam kesiapan karir peserta didik melalui pengembangan kapasitas. Berikut adalah sederet prestasi yang berhasil disabet oleh SDIT Logaritma Karanganyar dari awal berdiri:

a. Tingkat Internasional

Meraih Medali Perak dalam Internasional Mathematics and Science Olympiad (IMSO) Tahun 2016

b. Tingkat Nasional

1. Finalis Olimpiade Sains Kuark (OSK)

2. Meraih Medali Emas dan The Best Theory Olimpiade Sains Kuark (OSN) Tahun 2016

c. Tingkat Provinsi

1. Juara 1 Lomba Olimpiade Sains Nasional (OSN) Cabang IPA Tahun 2016

2. Lomba MAPSI Cabang Lomba Karya Ilmiah Islami (LKTI) mewakili Kabupaten Kebumenke Tk Provinsi Tahun 2017

3. Juara harapan 3 Lomba Olimpiade SainsN asional (OSN) Cabang IPA Tahun 2015

d. Tingkat Karesidenan

Juara 2 Lomba POPDA Cabang Bola Mini Tahun 2018

e. Tingkat Kabupaten

1. Juara 1 Lomba POPDA Cabang Bola Mini Tahun 2018

2. Juara 1 Lomba MAPSI Cabang Lomba Karya Tulis Islami (LKTI) Putri Tahun 2017

3. Juara harapan 1 Olimpiade Sains Nasional (OSN) Cabang Matematika Tahun 2016

4. Juara 2 Olimpiade Olahraga Siswa Nasional (O2SN) Tahun 2016

5. Juara 2 Lomba Olimpiade Sains Nasional (OSN) Cabang IPA Tahun 2015

6. Juara 1 Lomba Wood ball Yunior Kategori SD Tahun 2015

f. Tingkat Kecamatan

1. Juara 1 Lomba FLS2N Cabang Melukis Tk. Kecamatan Tahun 2019

2. Juara 2 Lomba FLS2N Cabang Pianika Tk. Kecamatan Tahun 2019

3. Juara 2 Lomba FLS2N Cabang Baca Puisi Tk. Kecamatan Tahun 2019 
4. Juara 3 Lomba FLS2N Cabang Pantomim Tk. Kecamatan Tahun 2019

5. Harapan 2 Lomba FLS2N Cabang Cipta Puisi Tk. Kecamatan Tahun 2019

6. Juara 1 POPDA Cabang Renang Putri Gaya Bebas 50 meter Tahun 2018

7. Juara 1 POPDA Cabang Renang Putri Gaya Kupu - kupu 100 meter Tahun 2018

8. Juara 1 POPDA Cabang Renang Putri Gaya Bebas 100 meter Tahun 2018

9. Juara 1 POPDA Cabang Renang Putri Gaya Kupu - kupu 100 meter Tahun 2018

10. Juara 1 POPDA Cabang Renang Putri Gaya Dada 100 meter Tahun 2018

11. Juara 1 POPDA Cabang Renang Putri Gaya Punggung 100 meter Tahun 2018

12. Juara 1 POPDA Cabang Renang Putra Gaya Bebas 100 meter Tahun 2018

13. Juara 1 POPDA Cabang Panahan 20 meter Putra Tahun 2018

14. Juara 1 POPDA CabangPanahan 20 meter PutriTahun 2018

15. Juara 1 POPDA CabangSepak Bola Mini TkKecamatanTahun 2018

16. Juara 1 Lomba POPDA Cabang Bola Voli Putra Tahun 2018

17. Juara 1 Lomba MAPSI CabangLombaKaryaTulisIslami (LKTI) PutriTahun 2017

18. Juara 1 Lomba MAPSI CabangSeniKhat Al Qur'an Putra Tahun 2017

19. Juara 1 Lomba MAPSI Cabang Teknologi Informatika dan Komunikasi Islam (TIKI) PutriTkKecamatanTahun 2017

20. Juara 1 Lomba MAPSI Cabang Mata Pelajaran Pendidikan Agama Islam dan Gebsa Putri Tahun 2017

21. Juara 1 Lomba MAPSI Cabang Mata Pelajaran Pendidikan Agama Islam dan Gebsa Putra Tahun 2017

22. Juara 1 Lomba Cerdas Cermat Tahun 2017

23. Juara 1 Lomba TIK Islami Putri (MAPSI) Tahun 2015

24. Juara 1 UjianSekolah Se-Kecamatan Karanganyar Tahun 2014/2015

25. Juara 2 POPDA Cabang Bulutangkis Putri Tahun 2018

26. Juara 2 POPDA Cabang Renang Putra Gaya Dada 100 meter Tahun 2018

27. Juara 2 POPDA Cabang Panahan 20 meter Putra Tahun 2018

28. Juara 2 POPDA Cabang Panahan 20 meter PutriTahun 2018

29. Juara 2 Lomba MAPSI Cabang Seni Hifzdil Qur'an Putra Tahun 2017

30. Juara 2 Lomba MAPSI CabangSeniTilawatil Qur'an Putra Tahun 2017

31. Juara 2 Lomba Cipta Cerita Islami Putri (MAPSI) Tahun 2015

32. Juara 2 Lomba MTQ Putra dan Putri (MAPSI) Tahun 2015

33. Juara 2 Lomba Kaligrafi Putri (MAPSI) Tahun 2015

34. Juara 2 Lomba Khitobah Putri (MAPSI) Tahun 2015

35. Juara 3 POPDA Cabang RenangPutri Gaya Bebas 50 meter Tahun 2018

36. Juara 3 POPDA Cabang RenangPutri Gaya Bebas 100 meter Tahun 2018

37. Juara 3 POPDA CabangRenang Putra Gaya Bebas 50 meter Tahun 2018

38. Juara 3 POPDA Cabang Renang Putra Gaya Dada 100 meter Tahun 2018

39. Juara 3 Lomba MAPSI Cabang Teknologi Informatika dan Komunikasi Islam (TIKI) Putra Tahun 2017

40. Juara 3 Lomba MAPSI Cabang Seni Tilawatil Qur'an PutriTahun 2017

41. Juara 3 Lomba Panahan KaranganyarTahun 2015

SD IT Logaritma Karanganyar merupakan salah satu sekolah di tingkat pendidikan dasar yang memiliki basis pendidikan Islam cukup kental dibandingkan sekolah umum. SDIT 
Universitas Ma'arif Nahdlatul Ulama Kebumen

Logaritma senantiasa berusaha untuk menanamkan dasar-dasar keislaman kepada pesserta didiknya. Adapun usaha untuk menumbuhkan nilai-nilai ajaran islam dilakukan melalui pembiasaan peningkatan akhlak terpuji (Akhlakulkarimah). Setelah adanya pembiasaan tersebut diharapkan mampu menjadi dasar untuk menanamkan pendidikan akademik sehingga memiliki kepribadian yang mulia dan peduli terhadap lingkungan sekitar.

Pendidik yang mengabdi untuk SDIT Logaritma juga merupakan pendidik pilihan yang memiliki ketrampilan serta sikap yang sesuai dengan kompetensi yang ditetapkan oleh yayasan. Adapun kompetensi tersebut diantaranya memiliki sikap sabar dalam mendidik, mengasah dan mengasuh peserta didik, dengan adanya kompetensi tersebut diharapkan akan mampu menciptakan tingkat kepercayaan yang tinggi dari masyarakat terutama para orang tua untuk menyekolahkan anak-anak mereka di SDIT Logaritma Karanganyar. Berdasarkan hasil wawancara yang telah dilakukan oleh penulis dengan beberapa orang tua atau wali murid yang dilakukan pada tanggal 21 dan 22 Juli 2020, sebagian besar dari mereka mengungkapkan bahwa latar belakang atau alasan mereka memilih SD IT Logaritma sebagai tempat bagi anak-anaknya untuk menuntut ilmu adalah karena mereka percaya bahwa SDIT Logaritma tidak hanya mengutamakan aspek akademis, akan tetapi juga mampu mendidik siswa baik dari segi akademis maupun Akhlak mulia secara utuh. Kenaikan jumlah peserta didik setiap tahunnya dapat dilihat pada tabel dibawah ini:

Tabel 1. Rincian Jumlah Siswa SDIT Logaritma Tahun pelajaran 2018-2020

\begin{tabular}{cccc}
\hline \multirow{2}{*}{ Kelas } & & \multicolumn{3}{l}{ Jumlah Siswa } \\
\cline { 2 - 4 } & $2018 / 2019$ & $2019 / 2020$ & $2020 / 2021$ \\
\hline I & 74 siswa & 77 siswa & 72 siswa \\
\hline II & 81 siswa & 75 siswa & 77 siswa \\
\hline III & 65 siswa & 83 siswa & 76 siswa \\
\hline IV & 59 siswa & 61 siswa & 81 siswa \\
\hline V & 61 siswa & 59 siswa & 61 siswa \\
\hline VI & 52 siswa & 60 siswa & 59 siswa \\
\hline Jumlah & 392 siswa & 415 siswa & 426 siswa
\end{tabular}

Sumber: diolah data primer

SD IT Logaritma senantiasa berusaha untuk terus meningkatkan kualitas pendidikan bagi peserta didiknya, hal tersebut dilakukan melalui program-program kegiatan yang bertujuan untuk meningkatkan kecerdasan dengan tetap memperhatikan segenap perbedaan karakteristik yang dimiliki oleh setiap siswa. Pembelajaran yang diterapkan di SD Islam terpadu Logaritma Karanganyar tidak hanya terfokus pada pendidikan akademik saja, melainkan juga memperhatikan pendidikan agama dan fasilitasi bakat serta minat dan potensi anak didik dalam berbagai kegiatan yang ada. Untuk memenuhi tuntutan zaman SD Islam terpadu Logaritma Karanganyar disamping membekali siswanya dengan ilmu umum dan agama akan tetapi juga dengan life skill sebagai bekal mereka untuk menghadapi tantangan zaman dan agar mereka bisa survive the life. Pendidikan kecakapan hidup (life skills) adalah pendidikan yang memberikan 
Universitas Ma'arif Nahdlatul Ulama Kebumen

kecakapan personal, kecakapan sosial, kecakapan intelektual, dan kecakapan vokasional untuk bekerja atau usaha mandiri.

SD Islam Terpadu Logaritma Karanganyar merupakan salah satu Sekolah Dasar yang membekali muridnya dengan life skill dengan berbagai program yang tersusun secara sistematis dan diselenggarakan secara teratur dan berkala. Dari hasil observasi dan wawancara peneliti tentang life skill sebagai penguatan Personal Branding Siswa di SD Islam Terpadu Logaritma Karanganyar, dapat disimpulkan bahwa life skill yang diterapkan di SD Islam Terpadu Logaritma Karanganyar mencakup semua skill yaitu personal, thinking, social, academic dan vocasional. Hal ini diaplikasikan pada kegiatan-kegiatan sekolah seperti:

a. Kegiatan Ekstrakulikuler (Murotal, Kaligrafi, MTQ, Bina Lukis, Bina Sastra, Bela Diri, Sepak Bola, Kids Atletik, Tata Boga, Bina Vokalia, Biola, Literasi, Pramuka)

b. Kegiatan Bina Prestasi (Seni, Olahraga, Mata Pelajaran)

c. Kegiatan Kokulikuler (Study Industri, Market Day, Mukhayam, Khotmil dan Tahfidz, Tahfidz Camp, Out Bond, Study Tour, Pesantren Ramadhan)

Banyak kegiatan-kegiatan sekolah yang mengarah kepada life skill, dan dari hasil penelitian di atas akan dipetakan dengan penjelasan berikut ini:

a. Kegiatan keagamaan seperti shalat wajib berjamaah, shalat dhuha, dan tadharus di sekolah, kegiatan ini dilakukan untuk membentuk siswa menjadi manusia yang bertakwakepada Allah dan berakhlakulkarimah. Ini bentuk dari pengembangan life skill dari personal skill dan academic skill.

b. Pengajaran pengetahuan agama dan pengetahuan umum seperti pembelajaran di kelas. Kegiatan ini dilakukan untuk mempersiapkan mental, wawasan yang luas, cakrawala pemikiran dan kematangan ilmu pengetahuan para siswa agar mampu memecahkan masalah yang dihadapkan kepada mereka. Ini bentuk dari pengembangan life skill dari academic skill.

c. Keorganisasian seperti pengurus kelas dan organisasi pramuka. Kegiatan ini dilakukan untuk membekali siswa agar bias melakukan kerjasama, bertenggang rasa, bertanggungjawab serta dapat bersosialisasi dengan baik. Ini bentuk dari pengembangan life skill dari personal skill dan social skill.

d. Kegiatan Mukhayam/kemah, Out Bond, Study Tour, Pesantren Ramadhan, kegiatan ini dilakukan untuk mempersiapkan mental, wawasan yang luas, cakrawala pemikiran dan kreatifitas para siswa agar mampu memecahkan masalah yang dihadapkan kepada mereka. Ini bentuk dari pengembangan life skill dari personal skill, social skill dan academic skill.

e. Muhadharah, muhadatsah. Kegiatan ini dilakukan untuk mengembangkan keterampilan berbahasa siswa serta agar siswa lebih percaya diri akan kemampuan yang mereka miliki. Ini bentuk dari pengembangan life skill dari academic skill,sosial skill dan personal skill.

f. Pramuka. Kegiatan ini dilakukan untuk membekali para siswa agar menjadi siswa yang tangguh baik secara fisik ataupun mental serta menjadikan siswa yang percayadiri. Ini bentuk dari pengembangan life skill dari personal skill dan social skill. Seni dan olah raga seperti seni, vokal, rebana, senilukis, seni letter, senigambar,batik, bulutangkis,sepak bola, panahan, renang dan lain-lain. Kegiatan ini dilakukan untuk mengembangkan minat,bakat serta kreativitas para siswa. Ini bentuk dari pengembangan life skill dari vocasional skill. 
JURNAL KRIDATAMA SAINS DAN TEKNOLOGI

Penguatan Personal Branding Siswa Melalui Pendidikan Kecakapan Hidup (Life Skills Education) Di SD Islam Terpadu Logaritma Karanganyar Kebumen Vol. 03 No.02 2021 E-ISSN: 2685-6921

Universitas Ma'arif Nahdlatul Ulama Kebumen

g. Literasi, Jurnalistik. Kegiatan ini dilakukan untuk memacu kreativitas siswa untuk berkarya membuat tulisan, karyatulis yang baik dan benar. Karyatulis mereka ditampilkan di madding baik di sekolah ataupun di rumah. Ini bentuk dari pengembangan life skill dari academic skill.

h. Kewirausahaan seperti bazar, Market Day dan CCM, study industry, mengajarkan para siswa ketrampilan, wiraswasta, usaha dan tata jualbeli yang baik dan benar menurut syariat Islam. Ini bentuk dari pengembangan life skill dari vocasional skill. Dan masih banyak kegiatan-kegiatan yang lainnya.

Proses pengembangan life skill yang diselenggarakan oleh SD IT Logaritma Karanganyar sudah berlangsung dengan cukup baik. Kondisi ini didukung oleh keterampilan yang diberikan diminati oleh siswa, ini terlihat dari keaktifan siswa selama kegiatan berlangsung. Komposisi materi sudah sesuai yaitu lebih banyak praktek dari pada teori. Penggunaan metode dan pendekatan sudah tepat sesuai materi pembelajaran dan kondisisantri. Ustadzah Dinul, menyatakan: bahwa "SD IT Logaritma Karanganyar melakukan upaya pengembangan life skill dengan tiga tahap yaitu tahap pengajaran, pembiasaan dan penugasan".

\section{Kesimpulan}

Berdasarkan rumusan penelitian, paparan data dan temuan penelitian maka hasil penelitian dapat disimpukan sebagai berikut:

a) SD Islam Terpadu Logaritma Karanganyar dalam mengembangkan personal skill dibuktikan dengan adanya kegiatan sholat wajib berjamaah, sholat dhuha, tadarus, keorganisasian pramuka, mukhayam, Study Tour, Study Industri, Out bond, pesantren ramadhan, English club;

b) SD Islam Terpadu Logaritma Karanganyar dalam mengembangkan thingking skill dibuktikan dengan adanya kegiatan keorganisasian kelas, pramuka, mukhayam, Tahfid, Study Tour, Study Industri, Market Day;

c) SD Islam Terpadu Logaritma Karanganyar dalam mengembangkan social skill dibuktikan dengan adanya kegiatan Mukhayam/kemah, Study Tour, Study Industri, Market Day, Pesantren ramadhan, English Club;

d) SD Islam Terpadu Logaritma Karanganyar dalam mengembangkan academic skill dibuktikan dengan adanya kegiatan Mukhayam/kemah, Tahfid, Study Tour, Study Industri, Market Day, literasi.

e) SD Islam Terpadu Logaritma Karanganyar dalam mengembangkan vocational skill dibuktikan dengan adanya kegiatan Kewirausahaan seperti bazar, Market Day dan CCM, study industry.

Kegiatan di SD IT Logaritma yang meliputi lima skill dalam hal ini personal, thinking, social, academic, dan vocatiaonal skill, sangat mendukung penguatan pada personal branding siswa. Oleh karena itu, dengan adanya personal branding dan life skill yang kuat dan baik, siswa atau santri akan bisa menghadapi pergulatan dan persaingan hidup di era globalisasi ini. Dimana yang mempunyai personal branding atau skill yang kuat, itulah yang bisa bersaing dan bertahan. 
JURNAL KRIDATAMA SAINS DAN TEKNOLOGI

Penguatan Personal Branding Siswa Melalui Pendidikan Kecakapan Hidup (Life Skills Education) Di SD Islam Terpadu Logaritma Karanganyar Kebumen

Vol. 03 No.02 2021

E-ISSN: 2685-6921

\section{Daftar Pustaka}

Universitas Ma'arif Nahdlatul Ulama Kebumen

Anwar, M. A. (2017). Manajemen Kelembagaan Pondok Pesantren. Yogyakarta: Pustaka Ilmu.

Asmani, J. M. (2011). Peran Pesantren dalam Kemerdekaan dan Menjaga NKRI. Yogyakarta: Aswaja Pressindo.

Azra, A. (2000). Pendidikan Islam Tradisi dan Modernisasi Menuju Milenium Baru. Ciputat: Logos Wacana Ilmu .

FIP-UPI, T. P. (2007). Ilmu dan Aplikasi Pemdidikan Bagian IV: Pendidikan Lintas Bidang. Jakarta: IMTIMA.

Hasanah, U. (2019). Upaya Pondok Pesantren dalam Mengembangkan Life Skill Santri. In Tesis (p. hlm. 83). Surabaya: Universitas Islam Negeri Sunan Ampel Surabaya.

Rizqi Azizah, A., \& Sa’bani, F. (2020). TINGKAT KEDISIPLINAN PESERTA DIDIK

DALAM PEMBELAJARAN PENJASORKES KELAS V SD IT VIP AL HUDA

KEBUMEN. JURNAL KRIDATAMA SAINS DAN TEKNOLOGI, 2(02), 131-140.

Retrieved from https://jurnal.umnu.ac.id/index.php/kst/article/view/85

Sagala, S. (2017). Human Capital. Depok: Kencana.

Sugiyono. (2014). Memahami Penelitian Kualitatif. Bandung: ALFABETA.

Sutrisna, E. (2010). Jurus Jitu Meroketkan Bisnis. Jakarta: PT. Gramedia Pustaka Utama.

Qardhawi, Y. A. (1980). Pendidikan Islam dan Madrasah Hasan Al Banna. Jakarta: Bulan Bintang. 